French budget

\section{Spending is slashed but not for science}

"THE War Budget" screamed the headline from the French newspaper Libération last week, in response to the announcement of one of the most severe French budgets since the Second World War. Government spending in 1984 is to increase 6.3 per cent (about the same as inflation) compared with projected economic growth of 1 per cent. Given a self-imposed limit of a 3 per cent budgetary deficit, the difference means FF 60,000 million ( $£ 5,000$ million) of new taxes. The results: Prime Minister Pierre Mauroy's popularity in opinion polls has plunged to 25 per cent; and President Mitterrand made an unprecedented $1 \frac{1}{2}$-hour appearance on television last Thursday to defend his government's policy. Not the circumstances, one might think, in which an expansionist scientific policy might flourish. But it has, and French thinking now aims at extending this policy to the whole of Europe.

While most government departments are facing constant or reducing budgets in real

\section{IMAGE UNAVAILABLE FOR COPYRIGHT REASONS}

terms, Laurent Fabius's ministry of industry and research will benefit from a 15.5 per cent increase in monetary terms. Much of the cash will go to support investment in the massive nationalized industry sector, but basic research will still see a 12.5 per cent increase - or 6 to 7 per cent in real terms. The French franc may have lost a lot of ground against the dollar last year, but these figures mean that French science will nevertheless be defended in 1984, and that the political will to support it remains very strong.

Even Jean-Pierre Chevènement, former minister of research and industry and political architect of present French science policy, said last week that he thought the science budget was "good, in the circumstances". This is strong praise, from a man who resigned over what he considered to be the government's excessively cautious approach to spending. Research had become rather "a fashion" in France, he said in an interview with Nature, "and while I don't believe in fashions this is a good one .... I'm pleased to think I had something to do with launching it."

Research, development and innovation have become this government's flag of hope. "We might become Greece to Europe's Rome" one ministry official said last week. And both the President and Prime Minister, on separate occasions, emphasized their reliance on a technological new dawn. President Mitterrand, in a ceremony breaking ground for the new accelerator LEP, at the European Organization for Nuclear Research (CERN) near Geneva, emphasized the European connection: Europe must not lose its place in the "third industrial revolution", he said. To keep its place, Europe should follow France, he implied. To this end, France would launch "new initiatives" on research when the presidency of the Council of the EEC next reverts to French hands. (One of these, for example, will concern a real improvement of mobility of researchers in Europe.)

The feeling in Paris is clearly this: France, with its 50 million people, is too small both economically and scientifically to succeed alone in the brave new world of the 1990s and the next century. For even France to succeed, Europe must join scientific hands. A recent agreement between British, French and West German computer companies to set up a joint research centre in Munich is widely seen in Paris as a good sign: the cooperation should not all be through Brussels, but by a strong network of two-, three- and multiway agreements - and Sweden, Switzerland and Austria (outside the EEC) should join in too. Thus, shortly, minister Laurent Fabius - a passionately convinced European - plans to visit certain European capitals to drum up support for an extension of such plans. In basic research, Pierre Papon - the director-general of the principal French research council, the CNRS - is also planning a European tour, again aimed at a real increase in cooperative effort. Papon says he is "absolutely certain" that the future of Europe depends on the success of such cooperation.

But, as the Prime Minister Pierre Mauroy said at Orsay (the scientific centre south of Paris) last Monday, it all depends on researchers becoming more involved with industry, and on industry taking account of science. Big industry in France increased its research spending last year, but only a little (about 5 per cent, according to some estimates); and small-to-medium industry has stood still. "State and industry must collaborate to devote a greater part of the national wealth to research and development"' said Mauroy. $\mathrm{He}$ also urged that researchers be encouraged to create their own businesses - a close echo of the policy of Mauroy's opposite number across the Channel.

Robert Walgate

\title{
CERN breaks new ground
}

THE French and Swiss Presidents were doing spadework at the European Organization for Nuclear Research (CERN) last week - breaking ground for CERN's next accelerator, LEP, which will straddle the French-Swiss border. CERN, said the French President, had regained for Europe "a dominant place in this domain of physies and high energies"' and perfectly illustrated the kind of political cooperation that was now needed in Europe in all sciences. Beams all round.

In the first version, LEP will collide electrons and positrons at sufficient energy to make copious numbers of $Z^{\circ}$ particles, the neutral partners of the triplet $\left(Z^{\circ}, W^{+}\right.$and $\left.W^{-}\right)$whose exchange among particles results in the weak force. A later version of LEP could enable it to reach the Ws.

However, the reader might say, has CERN not already discovered these particles? Indeed it has, but only in small numbers. LEP is capable of making thousands a day, and such statistics will allow a much more detailed analysis of the particles - and so provide a severe test of the Weinberg-Salam unified electro-weak model that predicted their existence and properties. LEP will also be able to work at other energies and on other particles such as the expected top quark.

Even so, given the $\mathbf{f 3 0 0}$ million cost of LEP, some heart-searching is setting in. The $p-\bar{p}$ collider that found the $Z^{\circ}$ and $W s$ has been much more effective than expected - and hot competition is coming from California, where the Stanford Linear Accelerator Center (SLAC) is staging a cut-price ( $\mathbf{f 7 5}$ million) attack on LEP physics. Dr Burton Richter, Nobellist master-mind of this SLAC "single pass collider"' (SPC) said on Monday that his SPC could still be ready by October 1986, compared with LEP's 1988. SPC may take longer to run in than LEP, because of its new design, it may produce only onequarter the number of $Z^{\circ} \mathbf{s}$, and its detectors will be old, but it does threaten to cream the best of LEP physics before LEP even turns on.

Robert Walgate 